\title{
Investment Criterion in Real Option Models*
}

\author{
Jing-Hui Dong ${ }^{\mathrm{a}, \dagger}$ and Yoshio Iihara

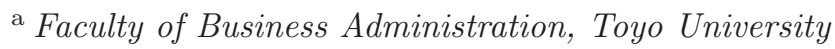

\begin{abstract}
We derive a new expression of investment criterion for real option models and give a new interpretation for the investment criterion. Given the required rate of return on investment $r$ and the irreversible investment cost $K$, the investment criterion for deterministic cash flow $X(t)$ is the marginal investment cost $r K$. For $X(t)$ follows geometric Brownian Motion (GBM), we derive a new expression of the investment criterion has a form of marginal investment cost $r K$ times a modification coefficient. This expression of the investment criterion is comparable to the criterion for deterministic cash flow. Thus our work leads to realizing the meaning of investment criterion for real option models more clearly. Moreover, we show the investment criterion for GBM with mixed exponential jumps can also be expressed by marginal investment cost $r K$ times a modification coefficient that is more complex than the GBM's. Furthermore, this form of investment criterion eases the comparative statics analysis. Finally, we discuss the case of investment cost by also following GBM, and derive an expression of the investment criterion which is comparable to the deterministic case.
\end{abstract}

Keywords: Investment criterion; real option model; marginal investment cost; geometric Brownian motion; jump diffusion processes

\footnotetext{
*Received: March 15, 2011; Accepted: July 3, 2011.

${ }^{\dagger}$ Corresponding author. Address: 5-28-20, Hakusan, Bunkyo-ku, Tokyo 112-8606, Japan; Phone: +81-33945-4923; E-mail: don@toyo.jp
} 


\section{リアルオプション・モデルの投資決定基準}

董 晶輝 ${ }^{\mathrm{a}}$, 飯原 慶雄

a 東洋大学経営学部

\section{1 はじめに}

リアルオプション・モデルでは，新規投資プロジェクトを実行するための投資支出 $K$ が不可 逆的で，プロジェクトからのキャッシュフロー $X(t)$ が幾何ブラウン運動

$$
X(t)=\mu X(t) d t+\sigma X(t) d W(t) \quad \sigma>0
$$

に従って変動するとき, 割引率 $r(>\mu)$ を一定とすると, プロジェクトの期待現在価值を最大 にする投資実行水準は

$$
x^{*}=\frac{\alpha}{\alpha-1}(r-\mu) K
$$

$\left(\alpha\right.$ は方程式 $\sigma^{2} z(z-1) / 2+\mu z-r=0$ の正根) であると示している. (2) 式は

$$
\frac{x^{*}}{r-\mu}=\frac{\alpha}{\alpha-1} K
$$

とすると, 左辺は将来発生するキャッシュフローの投資実行時点での期待現在価值であることか ら, 投資時点では, 将来のキャッシュフローの期待現在価值が投資コストよりも大になっている ことを示している.このことから, Dixit and Pindyck [2] は投資の正味現在価值 (net present value: NPV）が正のとき投資を実行するという単純な NPV ルールは正しくないと言ってい る ${ }^{1}$. しかし，投資のタイミングを求める問題は，ある時点で投資を実行すれば他の時点での投 資が不可能になることから，いわゆる相互排他的プロジェクト (mutual exclusive projects)の 選択問題であり，この際には正味現在価值の正負ではなく, 正味現在価值の最大のものが選択 されることになる，それでは，上の式が現在価值を最大にするものであることをどのように説 明したらよいのであろうか。ここでは，この問題を考えるために，まずキャッシュフローが確 定的である場合の最適投資基準を求め, その意味を考えてみる.

投資を実行したとき，時刻 $t$ で得られるキャッシュフローを $X(t)$ とする. $X(t)$ は時間 $t$ の関 数で, $t$ について連続で, 積分可能であると仮定する. 投資支出を $K$ とすると, 時刻 $\tau$ で投資 を実行したときの現在時刻 0 での正味現在価值 $N P V(\tau)$ は

$$
N P V(\tau)=\int_{\tau}^{\infty} X(t) e^{-r t} d t-K e^{-r \tau}=\int_{\tau}^{\infty}[X(t)-r K] e^{-r t} d t
$$

\footnotetext{
${ }^{1}$ Dixit and Pindyck [2, p.142] を参照.
} 
となり，正味現在価值最大のための必要条件は

$$
X(\tau)=r K
$$

となる. (4) 式は最適投資実行時点ではキャッシュフローが投資コストの利子費用と等しくなる ことを意味する．投資の実行を遅らせたとき発生する損失はその時点でのキャッシュフローで

り，得られる利益は投資コストの利子費用である。したがって，上の式は限界収入と限界支 出が等しくなる点が利益最大になるという経済学の限界原理を表している.

2 節では, 幾何ブラウン運動の場合の参入水準を確定的な場合のそれと比較可能な形に変形

た上で，その意味を考えてみる． 3 節では，幾何ブラウン運動にジャンプが加わる場合につ

ての考察し, この変形が比較静学分析を容易にすることを示す４４節では，投資費用が確率 的に変動する場合をとりあげ，確定的な場合と比較可能な形を提示する.

\section{2 最適投資水準を示す式の変形}

リアルオプション・モデルでの投資決定基準では，2次方程式

$$
f(z)=\frac{1}{2} \sigma^{2} z(z-1)+\mu z-r=0
$$

の正根 $\alpha$ が使用されているが，この 2 次方程式の正根を $\alpha$ ，負根を $\beta$ とすると

$$
f(z)=\frac{1}{2} \sigma^{2}(\alpha-z)(\beta-z)
$$

となるので，

$$
\frac{f(0)}{f(1)}=\frac{r}{r-\mu}=\frac{\alpha}{\alpha-1} \frac{\beta}{\beta-1}
$$

から，先のリアルオプション・モデルの投資決定基準は

$$
x^{*}=\frac{\beta-1}{\beta} r K=\left(1-\frac{1}{\beta}\right) r K
$$

という形に変形することができる。これは確定的キャッシュフローの場合の投資決定基準に $(1-1 / \beta)$ という修正項が掛った形になっている. $\beta$ は負根であるから, 投資決定水準は確定的 な場合より上昇する ${ }^{2}$.

Dixit and Pindyck [2] は最適投資水準を求める方法として，動的計画法と状態請求権分析の 2 種類のものを説明し, 動的計画法では, 割引率 $r$ を要求収益率とし, 状態請求権分析では, 割 引率 $r$ を無リスク金利としているが，ここでは，確定的キャッシュフローの場合との比較を行う

\footnotetext{
${ }^{2}$ Dixit and Pindyck [2] は, 次の変形

$x^{*}=\left(r+\sigma^{2} \alpha / 2\right) K$

から， $x^{*}$ が $r K$ より大になることを示しているが，幾何ブラウン運動以外のモデルを考えると，(7) 式の形の変形が 便利のように思われる。
} 
ため, 前者の考え方を踏襲し, 割引率は要求収益率とする. キャッシュフローが確定的な場合の 割引率はリスクフリー・レートであるが, 多くの現実の投資問題では, 将来のキャッシュフロー は確定的ではない.コーポレート・ファイナンスのテキストで, 実物投資の理論として現在価 值法を説明するときには, 将来の各時点でのキャッシュフローとして一つの值を示す. これは確 実な值というよりは, 予測值として一つの值を示したもので, 不確実な值の一つの代表值であ ると考えられる、前節で, 確定的キャッシュフローと呼んだものを不確実なキャッシュフローの 推定值とすれば, この際の割引率はプロジェクトのリスクに対応した要求収益率 (required rate of return) が使用されることになる. 以下では，確定的キャッシュフローはキャッシュフローの 推定值を指し, キャッシュフローを確率過程とする場合も, 1 個の推定值で代表する場合も, 割 引率 $r$ はともに要求収益率であるとする.

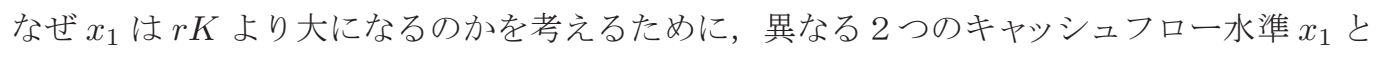
$x_{2}$ で投資を実行した場合の期待正味現在価值の差を求めてみる.ここでは, キャッシュフロー が幾何ブラウン運動のように連続的に変動するものとし, 現在時点 0 でのキャッシュフローの 水準 $X(0)$ を $x, x_{1}$ と $x_{2}$ への初到達時刻 (first passage time) を $t_{1}$ と $t_{2}$ とする.

$$
t_{i}=\inf \left\{t: X(t)=x_{i} \mid X(0)=x\right\} \quad(i=1,2)
$$

投資実行水準が $x_{i}$ のときの期待正味現在価值は

$$
\begin{aligned}
V\left(x ; x_{i}\right)=E\left[\int_{t_{i}}^{\infty} X(t) e^{-r t} d t-K e^{-r t_{i}} \mid X(0)=x\right] \\
=E\left[\int_{t_{i}}^{\infty}(X(t)-r K) e^{-r t} d t \mid X(0)=x\right]
\end{aligned}
$$

であるから， $x<x_{1}<x_{2}$ のときには，2つの投資実行水準での正味現在価值の差は

$$
V\left(x ; x_{1}\right)-V\left(x ; x_{2}\right)=E\left[\int_{t_{1}}^{t_{2}}(X(t)-r K) e^{-r t} d t \mid X(0)=x\right]
$$

となる。(9) 式は両者の差が $X(t)$ が $x_{1}$ に到達してから $x_{2}$ に到達するまでの間のキャッシュフ ローと投資の利子費用の差の期待現在価值となることを意味している．この值が負の場合， $x_{1}$ よりは $x_{2}$ で投資を実行した方がよいことになる.

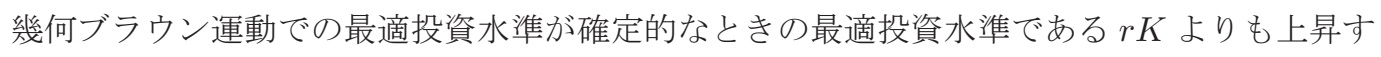
ることを確認するため, $d x$ を十分に小さな正の值とし, 投資実行水準として,$r K$ と $r K+d x$ の 2 つの水準を比較する. 幾何ブラウン運動の場合, $X(t)$ が $r K$ に到達した後で $r K$ を下回る 確率は正であるから, $d x$ が十分に小さい時には, $V(x ; r K)-V(x ; r K+d x)<0$ となり, $X(t)$ が $r K$ に到達したときに参入するよりも $r K+d x$ に到達したときに参入する方が期待現在価值 は大になる. 幾何ブラウン運動の場合, キャッシュフローが $r K$ に到達した直後に $r K$ 以下に なる確率が正であることが, 参入水準を確定的な場合のそれよりも高い水準にしている理由で ある。

最適実行水準を示寸 $(7)$ 式で幾何ブラウン運動のパラメータに関係するのは $\beta$ だけであり, $x^{*}$ は $\beta$ の増加関数で, $\beta$ は $\sigma$ の増加関数, $\mu$ の減少関数であるから, $\sigma$ の増加および $\mu$ の減少 が最適な投資実行水準を上昇させることが容易に理解される. 


\section{3 跳躍拡散過程での投資基準}

現実には，キャッシュフローの変動が幾何ブラウン運動に従うとは限らず，キャッシュフロー の変動が各種の突発的な要因によって大きく上下にシフトするような場合もある。ここでは，幾 何ブラウン運動に $m$ 種類の上方へのジャンプと $n$ 種類の下方へのジャンプが加わる場合を考え る.これらのジャンプは $\kappa_{i}(i=0,1,2, \cdots, m)$ および $\lambda_{i}(i=0,1,2, \cdots, n)$ をパラメータとする 互いに独立なポアソン過程にしたがって発生するとし, ジャンプ発生直前の $X(t)$ の值が $x$ のと き, 上方あるいは下方へのジャンプの後の $X(t)$ の值は $x Y_{i}$ あるいは $x / Z_{i}$ となり, $y_{i}=\log Y_{i}$ と $z_{i}=\log Z_{i}$ の確率分布は $\zeta_{i}$ と $\eta_{i}$ をパラメータとする指数分布であるとする ${ }^{3}$.この場合，レ ヴィ幕指数は

$$
\varphi(z)=\frac{1}{2} \sigma^{2} z(z-1)+\mu z+\sum_{i=1}^{m} \frac{\kappa_{i} z}{\zeta_{i}-z}-\sum_{i=1}^{n} \frac{\lambda_{i} z}{\eta_{i}+z}
$$

となり, Mordecki [4]は $r>\varphi(1)$ のとき，最適投資水準が

$$
x^{*}=\prod_{i=1}^{m}\left(\frac{\zeta_{i}-1}{\zeta_{i}}\right) \prod_{i=1}^{m+1}\left(\frac{\alpha_{i}}{\alpha_{i}-1}\right)(r-\varphi(1)) K
$$

となることを示している．ここで， $\alpha_{i}(i=1,2, \cdots, m+1)$ は方程式 $\varphi(z)-r=0$ の正根で ある・

方程式 $\varphi(z)-r=0$ の負根を $\beta_{i}(i=1,2, \cdots, n+1)$ とすると

$$
\varphi(z)-r=\frac{\frac{1}{2} \sigma^{2} \prod_{i=1}^{m+1}\left(z-\alpha_{i}\right) \prod_{i=1}^{n+1}\left(z-\beta_{i}\right)}{\prod_{i=1}^{m}\left(\zeta_{i}-z\right) \prod_{i=1}^{n}\left(\eta_{i}+z\right)}
$$

と表わされ， $\varphi(0)=0$ であることから，

$$
\frac{r}{r-\varphi(1)}=\prod_{i=1}^{m+1} \frac{\alpha_{i}}{\alpha_{i}-1} \prod_{i=1}^{n+1} \frac{\beta_{i}}{\beta_{i}-1} \prod_{i=1}^{m} \frac{\zeta_{i}-1}{\zeta_{i}} \prod_{i=1}^{n} \frac{\eta_{i}+1}{\eta_{i}}
$$

となり ${ }^{4}$, 上の最適参入水準は

$$
x^{*}=\prod_{i=1}^{n}\left(\frac{\eta_{i}}{\eta_{i}+1}\right) \prod_{i=1}^{n+1}\left(\frac{\beta_{i}-1}{\beta_{i}}\right) r K
$$

と表わすことができる. $\zeta_{i}, \eta_{i}, \alpha_{i}$ はその值の小さいものから， $\beta_{i}$ は絶対值の小さいものから 順に番号を付けると，

$$
\alpha_{i}<\zeta_{i}<\alpha_{i+1}, \quad-\beta_{i}<\eta_{i}<\beta_{i+1}
$$

となるので，

$$
\frac{\eta_{i}}{\left(\eta_{i}+1\right)} \frac{\left(\beta_{i}-1\right)}{\beta_{i}}>1, \quad \frac{\eta_{i}}{\left(\eta_{i}+1\right)} \frac{\left(\beta_{i+1}-1\right)}{\beta_{i+1}}<1
$$

3 ここで, $m$ と $n$ がともに 0 であると, この過程は幾何ブラウン運動になるので, 以下では, $m$ と $n$ のいずれか は正であるとする.

4 この関係は Boyarchenko [1] で，レヴィ過程とウィーナー=ホッフ因子分解の説明の中で触れられている. 
となり，

$$
\frac{\beta_{1}-1}{\beta_{1}} r K>x^{*}>\frac{\beta_{n+1}-1}{\beta_{n+1}} r K>r K
$$

となる.この場合も，投資水準は確定的なときの参入水準よりも上昇する ${ }^{5}$.

確率過程のパラメータの変化の影響を見る比較静学分析でも, (11) 式は $\varphi(1)$ を含むのに対 し, (13) 式はこれを含まないので, 分析が容易になる. 実際, 確率過程のパラメータのうち $\eta_{i}$ を除くパラメータを $a$ で表し $\varphi(z)$ の $z$ につての導関数を $\varphi^{\prime}(z)$ で表すことにすると,

$$
\frac{\partial x^{*}}{\partial a}=\sum_{i=1}^{n+1} \frac{1}{\beta_{i}\left(\beta_{i}-1\right)} \frac{\partial \beta_{i}}{\partial a} x^{*}=\sum_{i=1}^{n+1} \frac{1}{\beta_{i}\left(\beta_{i}-1\right)} \frac{-1}{\varphi^{\prime}(z)} \frac{\partial \varphi\left(\beta_{i}\right)}{\partial a} x^{*}
$$

となり, $\varphi^{\prime}\left(\beta_{i}\right)$ は負であるから ${ }^{6}$ 上の式の右辺の符号は $\partial \varphi\left(\beta_{i}\right) / \partial a$ の符号に等しくなり, $x^{*}$ が, $\sigma$ と $\kappa_{i}$ の増加関数, $\mu$ と $\zeta_{i}$ の減少関数となることが分かる ${ }^{7}$.

\section{4 投資費用も変動する場合}

前節までは投資費用が固定的であるとしたが，この節では投資費用も変動するものとする. 最初に, キャッシュフローと投資費用がともに確定的である場合, 寸なわち, 各時点での值を 1 個だけ推定する場合を考える. 投資を実行したときに得られる時点 $t$ でのキャッシュフローを $X(t)$, 時点 $t$ での投資費用を $K(t)$ とし, $K(t)$ は $t$ について微分可能な関数であるとする. 投 資費用の増加率を

$$
m_{k}(t)=\frac{d K(t)}{d t} / K(t)
$$

5 ジャンプがあるときは参入水準を飛び越えることがあるため, 前節の $t_{i}(i=1,2)$ の定義を

$$
t_{i}=\inf \left\{t: X(t) \geq x_{i} \mid X(0)=x\right\} \quad(i=1,2)
$$

とすることになるが，前節の説明は基本的にこの場合にも成り立つ.

6 負根の数は $n+1$ で, $\varphi(z)-r=0$ は $z=0$ では $-r$ になり, $-\eta_{i}(i=1,2, \cdots, n)$ の前後で, $+\infty$ と $-\infty$ にな り, $z=-\infty$ では $+\infty$ になるので, $\varphi^{\prime}\left(\beta_{i}\right)$ はすべて負になる.

${ }^{7} \lambda_{j}$ については, $\partial \varphi\left(\beta_{i}\right) / \partial \lambda_{j}$ が $i \leq j$ では正， $i>j$ では負になるため，簡単に符号を確定することは困難である が, 数值的に調べた限り, 実行水準は $\lambda_{j}$ の増加関数となっている. また, $\eta_{j}(j=1,2, \cdots, n)$ については

$$
\frac{\partial x^{*}}{\partial \eta_{j}}=\left(\frac{1}{\eta_{j}\left(\eta_{j}-1\right)}+\sum_{i=1}^{n+1} \frac{1}{\beta_{i}\left(\beta_{i}-1\right)} \frac{\partial \beta_{i}}{\partial \eta_{j}}\right) x^{*}
$$

となり右辺の第 1 項は正, 第 2 項以下は負になるが, 数値的に調べた限り, 第 2 項以下の効果が大で, 実行水準は $\eta_{j}$ の減少関数になっている. なお, ジャンプが下方だけの場合, すなわち, $m=0, n \geq 1$ のときには,

$$
x^{*}=\frac{\alpha}{\alpha-1}(r-\varphi(1)) K=\left(r+\frac{\sigma^{2}}{2} \alpha+\sum_{i=1}^{n} \frac{\lambda_{i} \alpha}{\left(\eta_{i}+1\right)\left(\eta_{i}+\alpha\right)}\right) K
$$

となるので，この式を利用することにより， $x^{*}$ が $\lambda_{i}$ の増加関数で, $\eta_{i}$ の減少関数になることを示すことができる. ま た，この式を利用することにより， $x^{*}$ が割引率 $r$ の増加関数であることも示すことができる. 
で表すと，時刻 $\tau$ で投資を実施したときの時刻 0 での正味現在価值は

$$
N P V(\tau)=\int_{\tau}^{\infty} X(t) e^{-r t} d t-K(\tau) e^{-r \tau}=\int_{\tau}^{\infty}\left[X(t)-\left(r-m_{k}(t)\right) K(t)\right] e^{-r t} d t
$$

となり，正味現在価值の最大化のための必要条件は

$$
X(\tau)=\left[r-m_{k}(\tau)\right] K(\tau)
$$

となる，すなわち，投資を遅らせることにより得られる利益はその時点での投資費用の利子費 用と投資費用の増加分の差であり，キャッシュフローがこの值に等しくなる時点で投資を実行 するのが最適となる.

キャッシュフロー $X(t)$ と投資費用 $K(t)$ の変動がともに幾何ブラウン運動で, キャッシュフ ローについてのパラメータが $\mu_{1}, \sigma_{1}$ ，投資費用についてそれが $\mu_{2}, \sigma_{2}$ で，両者のウィーナー 過程の相関係数が $\rho$ である場合について, McDonald and Siegel [3] は $X(0)=x, K(0)=k$ の ときの期待現在価值を $V(x, k)$ としたとき, この関数が $x$ と $k$ の 次同次関数であることを利 用して,

$$
y=x / k, \quad U(y)=V(y, 1)
$$

とすると, $V(x, k)$ についての微分方程式が, $U(y)$ についての微分方程式

$$
\frac{1}{2} \sigma^{2} y^{2} U^{\prime \prime}(y)+\left(\mu_{1}-\mu_{2}\right) y U^{\prime}(y)-\left(r-\mu_{2}\right) U(y)=0 \quad\left(\sigma^{2}=\sigma_{1}^{2}-2 \rho \sigma_{1} \sigma_{2}+\sigma_{2}^{2}\right)
$$

となり，境界条件が

$$
U\left(y^{*}\right)=c y^{*}-1 \quad\left(c=1 /\left(r-\mu_{1}\right)\right)
$$

となることを示した。この場合の最適な投資水準 $y^{*}$ は, $\mu_{1}<r, \mu_{2}<r$ であると,

$$
\frac{1}{2} \sigma^{2} z(z-1)+\left(\mu_{1}-\mu_{2}\right) z-\left(r-\mu_{2}\right)=0
$$

の正根を $\alpha$ とすると

$$
y^{*}=\frac{\alpha}{\alpha-1}\left(r-\mu_{1}\right)
$$

となる ${ }^{8}$.この最適水準は, $(20)$ 式の負根を $\beta$ とすると, 2 節の場合と同様にして,

$$
y^{*}=\frac{\beta-1}{\beta}\left(r-\mu_{2}\right)
$$

と表現できる.

$$
\mu_{2}=\frac{d E[K(t)]}{d t} / E[K(t)]
$$

であるから，2 節の場合と同様に，確定的な場合の投資水準に対し，修正項 $(1-1 / \beta)$ が掛っ たものがこの場合の最適投資水準になる.

8これらの取扱については Dixit and Pindyck [2]にも説明されている. 
ここで得られた最適投資水準 $y^{*}$ は, 上の $(18)$ 式と $(20)$ 式から, $Y(t)$ の変動として,

$$
d Y(t)=\left(\mu_{1}-\mu_{2}\right) Y(t)+\sigma Y(t) d W(t)
$$

という幾何ブラウン運動を考え, 割引率を $r-\mu_{2}$, 投資費用を 1 としたときの最適投資水準に なっている。したがって，2つの参入水準に対する期待現在価值の差は

$$
t_{i}=\inf \left\{t: Y(t)=y_{i} \mid Y(0)=y\right\} ; \quad(i=1,2)
$$

とすると, $y>y_{1}>y_{2}$ のとき

$$
U\left(y ; y_{1}\right)-U\left(y ; y_{2}\right)=E\left[\int_{t_{1}}^{t_{2}}\left[Y(t)-\left(r-\mu_{2}\right) e^{-\left(r-\mu_{2} t\right.} d t \mid Y(0)=y\right]\right.
$$

となり，2節の説明と同様にして，この場合の最適投資水準が確定的な場合に比較して，投資 水準が上昇することが理解される.

この場合, 最適投資水準 $y^{*}$ は $\sigma, r, k$ の増加関数, $\mu_{1}, \mu_{2}$ の減少関数になっている.

\section{5 おわりに}

将来の各時点でのキャッシュフローについて, 1 つの值を推定し, それの現在価值を基準にし て, プロジェクトの価值を求める割引現在価值法に対し, リアルオプション・モデルでは, キャッ シュフローの動きを確率過程として把握してきた.ここでは, この二つのアプローチが基本的 に同一のものであることを示した. リアルオプション・モデルでの投資時点の決定問題は相互 排他的プロジェクトの選択であることから，従来のアプローチ（確定的キャッシュフローの場 合）では, 限界収入と限界支出が等しくなる時点で投資が実行されることを再確認したうえで, 一見，これとはかなり異なる基準のように見えるリアルオプション・モデルの投資決定基準も， 基本的には同一であるが，それに，修正項が掛った形になることを示した．このような修正が 必要になる理由は, 従来の基準に到達した直後に, その水準を下回る可能性があることにある. この結果, リアルオプション・モデルでは, 従来の基準よりも高い水準が最適水準となる.こ のことは, 従来型のアプローチを採用するときには, キャッシュフローの一時的な下降や突然 の下降が予想されるときには, 投資決定水準を従来型の水準より高める必要があることを示し ている ${ }^{9}$.ここで求めた結果は, ぞのような修正が必要になるかを明らかにした。 なお，この 表現は，3 節で示したように比較静学分析を容易にするという効果も持っている.

\section{謝辞}

本稿の一部分は日本経営財務研究学会, 日本リアルオプション学会で報告したものである. 匿 名の査読者および編集担当者のコメントより本稿が改善された，感謝を申し上げます．

\footnotetext{
${ }^{9} 3$ 節のモデルで, $\sigma=0, \mu \geq 0, n=0$ の場合, すなわち, 確率的に上方へ変動するが, 下方への動きがないとき には，最適な水準は $r K$ になることも，このことを示唆している.
} 


\section{リアルオプション・モデルの投資決定基準}

\section{参考文献}

[1] Boyarchenko, S. (2004). Irreversible decisions and record-setting news principles. American Economic Review, 94, 557-568.

[2] Dixit, A. K. and Pindyck, R. S. (1994). Investment under Uncertainty. Princeton University Press, Princeton. (日本語訳 :『投資決定理論とリアルオプション』, 川口有一郎等 訳，エコノミスト社，2002)

[3] McDonald, R. and Siegel, D. R. (1986). The value of waiting to investment. Quarterly Journal of Economics, 101, 707-728.

[4] Mordecki, E. (2002). Optimal stopping and perpetual options for Lévy processes. Finance and Stochastics, 6, 473-493. 